\title{
A study on phenological traits of Abies pindrow (Royle) Spach. in the different sites of Garhwal Himalayas, India
}

\author{
Haseeb U. R. Masoodi ${ }^{* 1}$, Dipika Rana ${ }^{2}$, Manisha Thapliyal ${ }^{1}$ and V. R. R. Singh ${ }^{4}$ \\ ${ }^{\mathbf{1}}$ Forest Research Institute, Dehradun (Uttarakhand), INDIA \\ ${ }^{2}$ Himalayan Forest Research Institute, Panthaghati, Shimla (HP), INDIA \\ ${ }^{4}$ Additional Principal Chief Conservator of Forests (P\&M), Shimla (HP), INDIA \\ *Corresponding author. E-mail: haseebgis@gmail.com
}

Received: February 10, 2016; Revised received: July 26, 2017; Accepted: January 23, 2018

\begin{abstract}
Phenology, the timing of various events in a species life cycle, is an important life history trait for both plants and animals. Dharali site situated in the highest altitudinal range i.e. $2800-3300 \mathrm{~m}$ above msl and showed the initiation of all the phenological characteristics i.e. leaf fall, leaf emergence, appearance of male and female strobili, pollination, cone maturation and seed dispersal in advance as compared to all the other sites. The comparison of the two years phenological data in all the sites (Mundali, Bhukki, Dheoban, Dharali) showed that in the year 2013 early leaf emergence, prolonged cone maturity and early seed dispersal were observed. Rise in temperature and change in climate in mountainous regions has caused the tree line to advance to higher elevations as temperatures have increased over the past few decades. In addition to changing their spatial distributions, plants are also changing their temporal niches.
\end{abstract}

Keywords: Abies pindrow, Climate change, Himalayas, Phenology, Phenophases

\section{INTRODUCTION}

Phenological studies of a species forms an essential component to detect the problem of regeneration and it can be defined as the study of cyclical biological events in plants that include flowering, leaf unfolding (or budburst), seed set, dispersal and leaf fall in relation to climatic conditions (Davi et al., 2011). Plant phenology has been proposed as an indicator of climatic difference and global change by the European Environmental Agency and the Intergovernmental Panel on Climate Change (IPCC, 2007). Long-term phenological records in trees, including spring events such as leaf unfolding and autumnal events of leaf colouring, have shown that a rise in global temperature generally leads to earlier timing of spring events (Menzel et al., 2006; Doi and Katano, 2008 and Chen and $\mathrm{Xu}, 2012$ ).

The timing of seasonal activities or phenology, is a fundamental aspect of plant functioning at organization levels ranging from the individual to the ecosystem (Forrest et al., 2010). It is an integrated response to the environmental conditions accomplishing growth and reproduction of species. For this reason, archives of phenological observations have assumed particular importance in the last decades because shifts in phenological events have pointed out changes in the environment (Menzel et al., 2006; Anderson et al., 2013) or a mismatch among species along food chains (Johnson et al., 2010). In plants, the phenology of growth represents a trade-off between environmental constraints and resource availability, and identifies the period when resources are acquired and used (Nord and Lynch, 2009). The growing season in temperaturelimited environments, for example, is an optimization between frost damage avoidance and maximization of annual carbon assimilation (Chuine, 2010).

For plants, spring events such as budburst and flowering occurr earlier (Parmesan, 2006; Miller-Rushing and Primack, 2008). These changes reflect in part changes in weather conditions, and a large number of studies have documented the effect of increasing temperature on the timing or the duration of phenological events (Cannel and Smith, 1986; Kramer, 1995; Chmielewski and Rotzer, 2001; Scheifinger et al., 2002; Menzel, 2003; Menzel et al., 2003; Chmielewski et al., 2004; Chen et al., 2005; Cleland et al., 2007; Menzel et al., 2008; Nordli et al., 2008); Shah et al., 2014; Kumar et al., 2017. In particular, in high-altitude regions, phenology is strongly influenced by snowmelt in addition to air temperature (Bliss, 1971; Inouye, 2008; Hulber et al., 2010; Wipf, 2010). Snow cover influences soil temperatures and delays spring phenology even in the tree vegetation layer which is characterized by having a substantial biomass above the snow layer. The aim of the current study was to analyse phe- 
nological characteristic of Abies pindrow at selected sites.

\section{MATERIALS AND METHODS}

Study site: The present study was undertaken in the state of Uttarakhand that lies in the latitudinal range of $28^{\circ} 43^{\prime}-31^{\circ} 28^{\prime} \mathrm{N}$ and longitudinal range of $77^{\circ} 34^{\prime}-81^{\circ}$ $03^{\prime}$ E with a geographical area of $53,483 \mathrm{~km}^{2}$ and forest area of $34651 \mathrm{~km}^{2}$. of the total geographical area, about $19 \%$ is under permanent snow cover, glaciers and steep slopes. Starting from the foot hills in the south, the state extends upto the snow-clad peaks of the Himadri making the Indo-Tibetan boundary.

Four sites bearing Abies pindrow forests were selected in the state of Uttarakhand for undertaking the present study. Two sites Mundali and Deoban fall under Chakrata forest division and Bhukki and Dharali sites fall under Uttarkashi forest division (Fig. 1). The altitudinal range of all the four sites varies between 2200 $3300 \mathrm{~m}$ above msl. The latitudinal and longitudinal ranges of all the four sites have been given in Table 1, which were collected from said sites with the help of GPS.

Methodology: Phenological studies were carried throughout the year and observations on the Leaf fall, Leaf emergence, Male strobili appearance, Female strobili appearance, Pollination, Cone maturity, Seed dispersal and Crown width $(\mathrm{m})$ parameters were recorded for the period of two years.

For taking these observations 15 trees were selected randomly at least $100 \mathrm{~m}$ apart at each selected site and these trees were marked for maintaining their identity throughout the study period. Meteorological observations for the study area during the year 2012-2013 are presented in Figs.2-5.

Climate: The climate of an area varies a lot depending upon its altitude and aspect. In the present context the study area falls in wet temperate and dry temperate zone. The northern aspect is cooler than the southern aspect. Precipitation is in the form of rains mainly during rainy season but snowfall occurs during winter months. The temperature ranges between minimum of $-4^{\circ} \mathrm{C}$ in the winters to maximum of $22^{\circ} \mathrm{C}$ in the summers with the average annual precipitation of 1100 $\mathrm{mm}$. There are three main seasons; the cool and relatively dry winter (December to March); the warm and dry summer (mid April to June); and a warm and wet period (July to mid September) called as the monsoon or rainy season. Apart from these main seasons, the transitional periods interconnecting rainy and winter, and winter and summer seasons are referred to as autumn (October to November) and Spring (February to March).

\section{RESULTS AND DISCUSSION}

Phenological studies were carried out at all the four

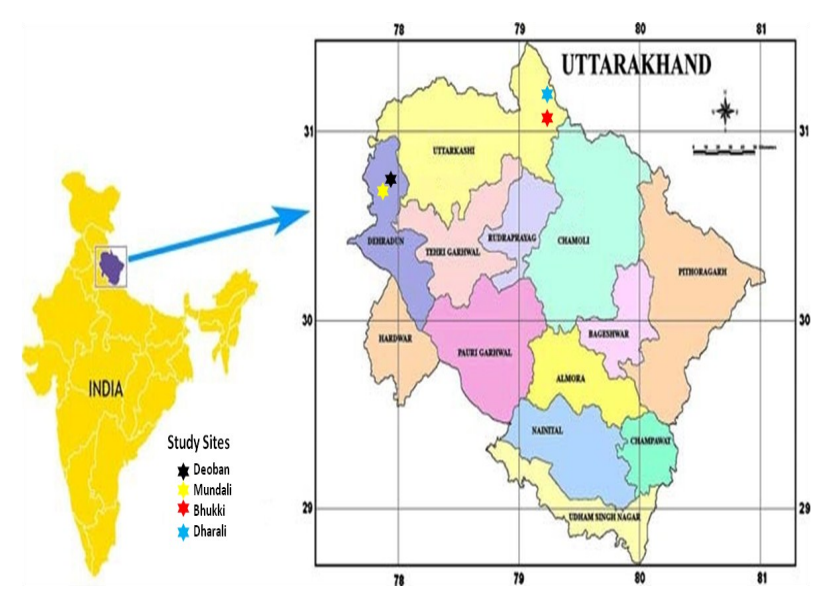

Fig. 1. Location map of the study sites.

sites i.e. Mundali, Deoban, Bhukki and Dharali for the years 2012 and 2013. All the phenological traits i.e. leaf fall, leaf emergence, appearance of male and female strobili, pollination, cone maturity seed dispersal and crown width were studied and compared for the two years.

The data for the year 2012 revealed that in Mundali the leaf fall initiated in the mid May while the leaf emergence started in the mid April up to mid May. The emergence of male strobili was noticed in the mid March upto early April whereas appearance of female strobili was observed in the early March up to mid April. Pollen dissemination started in the late April and lasted to the very end of May. Cones matured in the early October till early November whereas seed dispersal occurred in the last week of October till last week of November. Not many variations were observed in the phenological events in 2013 except for the seed dispersal that showed early onset by a week as compared to the previous year in the month of October during the year (2013) (Fig.6 ).

The phenological traits for Deoban situated at an altitude of 2500-2900 m showed the leaf fall in the middle of May which continued up to the middle of June whereas the leaf emergence was seen in the middle of April up to middle of May. The appearance of male and female strobili was observed in the middle of March, which continued up to middle of April. Pollination occurred in late April and continued up to late May. Cones matured in the mid October to mid November whereas seed dispersal occurred in the late October till late November (Fig.6). Similar trend was observed in the year 2013, for the phenological traits like leaf fall, leaf emergence, appearance of male strobili and pollination except for the early emergence of female strobili which was seen in the early March and continued up to early April and delayed seed dispersal which was noticed in the late October till late November (Fig.6).

In the site Bhukki, in the year 2012, leaf fall occurred in the early May and persisted up to the early June 
Table 1. Latitudinal and Longitudinal attributes of the study sites.

\begin{tabular}{lllllll}
\hline \multirow{2}{*}{ Forest Divisions } & Sites & Latitudinal Range (N) & Longitudinal Range (E) & Elevation (m) & Aspect & $\begin{array}{l}\text { Slope } \\
(\%)\end{array}$ \\
\hline \multirow{2}{*}{ Chakrata } & Mundali & $30^{\circ} 48^{\prime} 40.6^{\prime \prime}-30^{\circ} 49^{\prime} 02.6^{\prime \prime}$ & $77^{\circ} 55^{\prime} 39.9^{\prime \prime}-77^{\circ} 57^{\prime} 01.9^{\prime \prime}$ & $2300-2600$ & Western & $20-45$ \\
& Deoban & $30^{\circ} 44^{\prime} 42.0^{\prime \prime}-30^{\circ} 45^{\prime} 28.3^{\prime \prime}$ & $77^{\circ} 51^{\prime} 38.7^{\prime \prime}-77^{\circ} 52^{\prime} 29.5^{\prime \prime}$ & $2500-2900$ & North-West & $15-40$ \\
\multirow{2}{*}{ Uttarkashi } & Bhukki & $30^{\circ} 51^{\prime} 05.5^{\prime \prime}-30^{\circ} 52^{\prime} 08.3^{\prime \prime}$ & $78^{\circ} 41^{\prime} 40.0^{\prime \prime}-78^{\circ} 43^{\prime} 05.5^{\prime \prime}$ & $2200-2500$ & Eastern & $25-50$ \\
& Dharali & $30^{\circ} 00^{\prime} 13.3^{\prime \prime}-30^{\circ} 00^{\prime} 49.1^{\prime \prime}$ & $78^{\circ} 45^{\prime} 43.3^{\prime \prime}-78^{\circ} 46^{\prime} 56.5^{\prime \prime}$ & $2800-3300$ & Northern & $30-60$ \\
\hline
\end{tabular}

while, the leaf emergence was perceived in the mid April up to mid May. Male and female strobili appeared in the mid March and its growth continued till mid April. Pollination occurred in the mid April and continued up to mid May which was followed by cone formation. Cones started maturing in late September after that mature seeds get separated from the scales, loosened and fell away from the central axis. Seed dispersal began in the mid October and continued till mid November. Phenological traits in 2013 were alike, apart from leaf emergence which was observed in the early April upto early May (Fig. 6).

This study regarding phenology of Abies pindrow at Deoban, in the year 2012 revealed that leaf fall initiated in the early May and sustained up to the early June, while leaf emergence started in the early April with a peak in early May. The appearance of male strobili was noticed throughout March and appearance of female strobili was observed in the early March up to early April. Pollination occurred in the mid April and continued up to mid May. Cone ripened from late September upto late October while, seed dispersal oc-

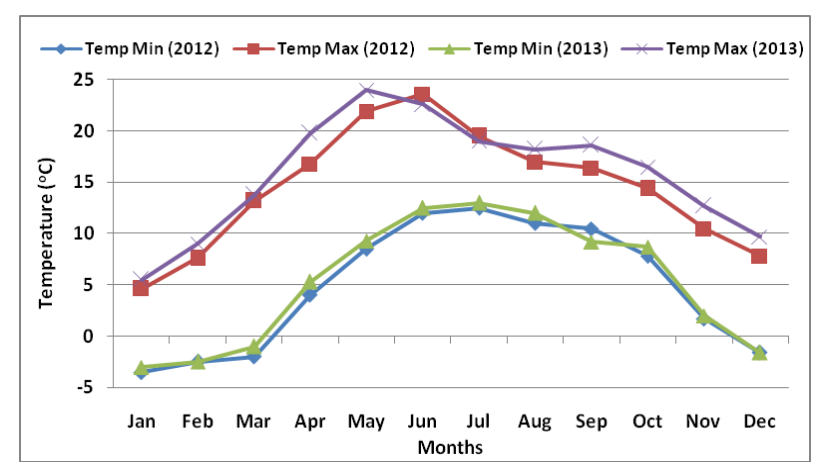

Fig. 2. Monthly mean maximum and minimum temperature during the year 2012-2013 at Chakrata Forest Division.

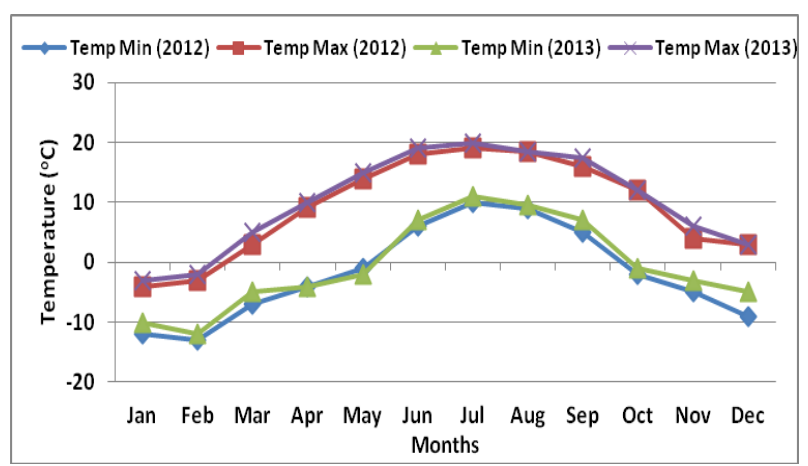

Fig. 3. Monthly mean maximum and minimum temperature during the year 2012-2013 at Uttarkashi Forest Division. curred in the early October till early November of 2012 (Fig. 6). For the year 2013, same trend was observed except for the early leaf emergence in late March to late April. Cone maturity prolonged up to early November whereas seed dispersal started early as compared to the previous year i.e. in the month of September (2013).

Dharali site situated in the highest altitudinal range i.e. 2800-3300 $\mathrm{m}$ above msl and showed the initiation of all the phenological characteristics i.e. leaf fall, leaf emergence, appearance of male and female strobili, pollination, cone maturation and seed dispersal in advance as compared to all the other sites. The comparison of the two years phenological data showed that in the year 2013 early leaf emergence, prolonged cone maturity and early seed dispersal were observed. Elevated temperature and climate change in mountainous regions has caused the tree line to advance to higher elevations as temperatures have increased over the past few decades (Jump et al., 2009). Reports of changes in the phenology of plants in response to climate change over the past few decades are numerous. In

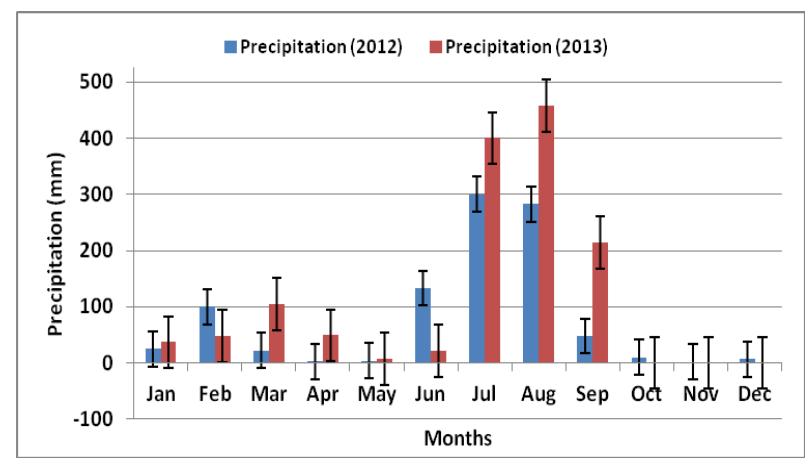

Fig. 4. Precipitation (mm) during the year 2012-2013 at Chakrata Forest Division.

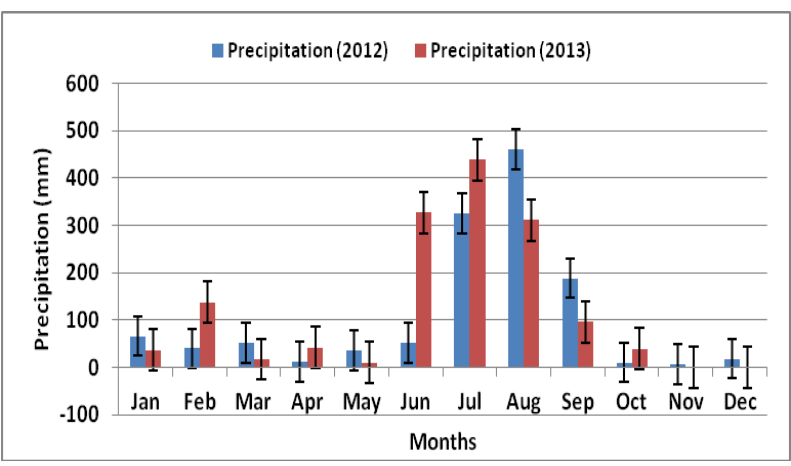

Fig. 5. Precipitation (mm) during the year 2012-2013 at Uttarkashi Forest Division. 
Haseeb U. R. Masoodi et al. / J. Appl. \& Nat. Sci. 10 (1): 178 - 184 (2018)

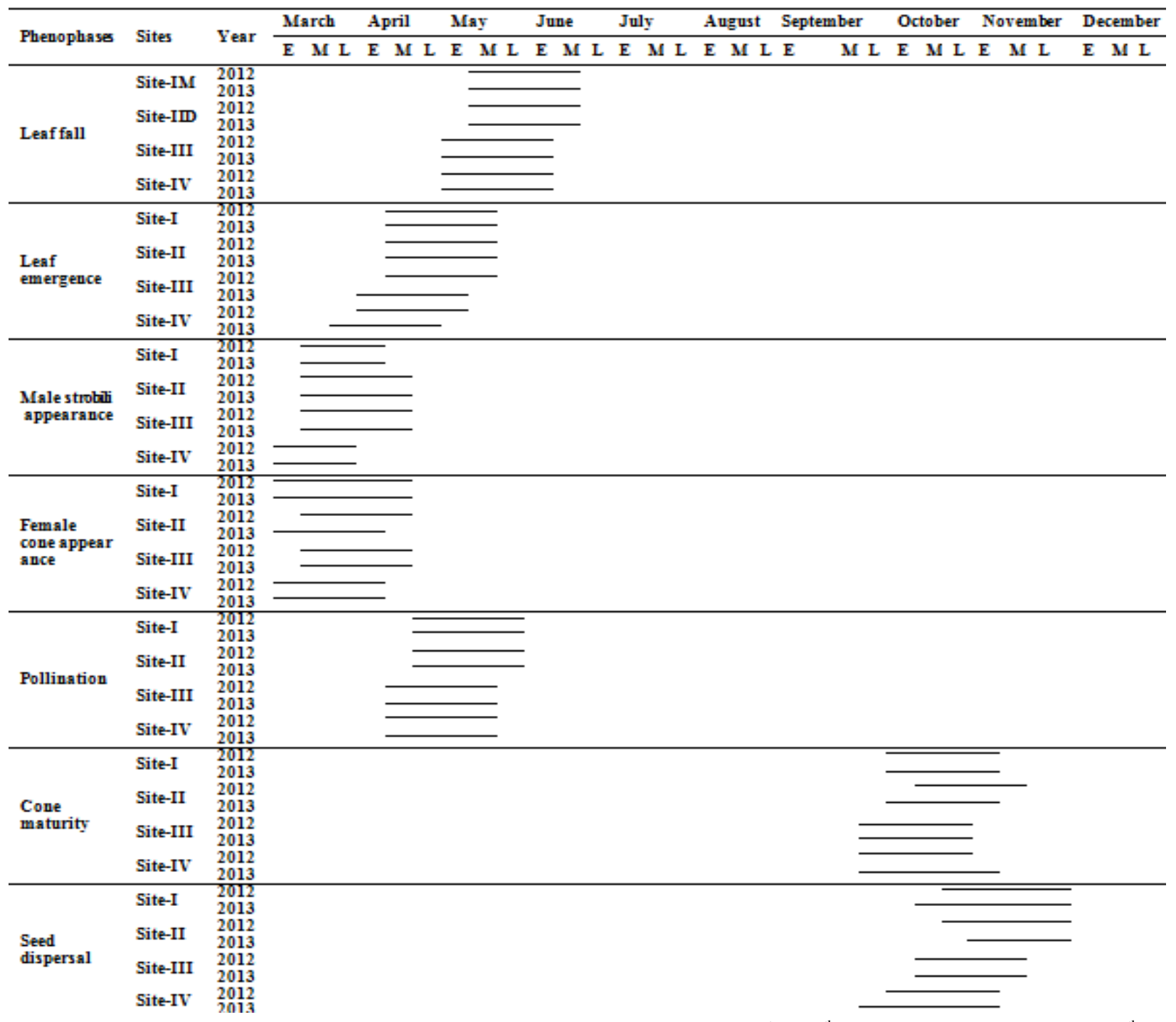

Site-I=Mundali, Site-II = Deoban, Site-III $=$ Bhukki, Site-IV $=$ Dharali, E $=$ Early $\left(\mathrm{I}^{\text {st }}\right.$ to $10^{\text {th }}$ day of the month $), M=M i d\left(11^{\text {th }}\right.$ to $20^{\text {th }}$ day of the month), $\mathrm{L}=$ Late $\left(21^{\text {st }}\right.$ to $30^{\text {th }}$ day of the month)

Fig. 6. Duration of different phenophases of Abies pindrow of four sites for the year 2012-13.

addition to changing their spatial distributions, plants are also changing their temporal niches (e.g. MillerRushing and Primack, 2008; Miller-Rushing and Inouye, 2009).

Species native to colder climates tend to have short growing season and low growth and productivity. At higher latitudes and altitudes, growth has to be completed within a limited time period and in less favourable conditions than in temperate climates (Chuine, 2010). Species adjust their phenology with shifted or compressed growth and reproduction phases, according to specific regional environmental drivers, local adaptations and individual plasticity to climate (Nord and Lynch, 2009; Diez et al., 2012). However, it is unclear if and how this pattern applies to the cambium and its phenology across taxonomic groups and locations.

Pellerin et al. (2012) studied tree phenology in the
Western Alps for birch, ash, hazel, spruce and larch and concluded that altitude was the main predictor of budburst and leafing dates with delays ranging from 2.4 to 3.4 days per $100 \mathrm{~m}$. Whereas studies conducted by Rossi et al., (2013) on phenology and growth patterns in conifers of the northern hemisphere concluded that the trees adjust their phenological timings according to linear patterns. Thus, shifts of one phenological phase are associated with synchronous and comparable shifts of the successive phases. The findings suggested that the length of the growing season and the resulting amount of growth could respond differently to changes in environmental conditions.

Talking about the phenological data of Deoban site which had an altitudinal range between 2500-2900 m above msl, a delay in phenological events compared to Dharali was observed. Similar trends were seen for Mundali except for the early appearance of female 
strobili and early cone maturity. Certain fluctuating trends for leaf emergence were observed in Bhukki in 2013 as appearance was little early as compared to previous year. This can be attributed to various environmental factors.

Environmental reasons specified for such changed phenology in high-altitude regions strongly influenced by snowmelt in addition to air temperature (Bliss, 1971; Inouye, 2008; Hulber et al., 2010; Wipf, 2010; Inouye and Wielgolaski, 2013). However, the snow layer also has a protective property in that, it protects vegetation from subzero temperatures associated with high-altitude diurnal variation in temperature during early spring. As climate warms, the phenologies of the lower trophic levels tend to change more drastically, and are in better synchrony with climate change than the phenology of the higher ones, leading to increased ecological mismatch (Both et al., 2009). Important plant events such as spring bud burst and flowering occur earlier in many locations, and appear to be a result of earlier snowmelt and higher temperatures (Parmesan, 2006). Similar trend was seen in the present study. The Alpine communities might be especially sensitive to changes in climate, due to their occurrence at high altitudes, exposure to lower temperatures, short growing seasons, and restricted distributions (Parmesan, 2006). Additionally, the effects of warming have become more severe at higher altitudes because changes to the snow-albedo feedback system hasten decreases in glacial extent and snow cover (Harte et $a l ., 1995)$. As a result, higher elevations that used to be covered in snow for longer periods of time are now warming at faster rates than the lower, snow-free regions (Clow, 2010). The same can be attributed for the phenological events seen for the above mentioned sites.

Whereas in some other studies it was concluded that earlier snowmelt may increase risk of frost damage for early flowering species (Inouye, 2008). As such, species might be expected to show a delayed phenology at high altitude compared to low altitude in order to prevent risk of frost damage. However, species have to complete their reproduction cycle within the relatively short vegetation period at high altitudes, constraining them to early budburst and/or flowering (Defila and Clot, 2005; Wipf, 2010).

However, perhaps due to the diversity of factors that plants use to determine their phenologies and their diversity of niches, different plant species alter their phenologies at different rates in response to climate change. According to studies conducted to date, snowmelt generally controls the flowering phenology of subalpine plants, and plants have a shorter time to develop and flower in these harsh conditions (Inouye et al., 2002). In the Rocky Mountains, USA, earlyflowering species-phenologies, in particular, have demonstrated a stronger correlation to snowmelt date to snowmelt than late-flowering species (Dunne et al., 2003, Miller-Rushing and Inouye 2009). Subsequent research has suggested that such dependence upon snowmelt date is species dependent (Forrest et al., 2010). Other factors affecting the timing and abundance of flowering in subalpine environments are changes in precipitation (Crimmins et al., 2010) and temperature (Hulber et al., 2010). Overall, broad trends suggest that early-flowering species are reacting more drastically to the rising temperatures than are late -flowering species (Miller-Rushing and Inouye, 2009). Crimmins et al., (2009) examined the range shift of a variety of different plants across a $1200 \mathrm{~m}$ altitude gradient in Arizona. They found that as ambient air temperature increased, plants had a variety of flowering range responses; some species shifted their flowering range upward, others contracted it upward, and others expanded it upward.

Studies till date have primarily been made on changes in phenology across altitude in montane and alpine regions. In Argentina, temperature appears to influence the phenology of bud burst and flowering of Nothophagus pumilio in montane forests; bud burst and flowering were both delayed at higher altitudes where temperatures were colder (Rusch, 1993). But altitude may not be the factor directly affecting phenology, but temperature, which co-varies with altitude, was the important factor. In contrast, a study of several plant species across the European Alps did not find that plant phenology significantly changed as a function of altitude, though phenology did change as temperatures warmed over the past few decades (Ziello et al., 2009).

Factors such as photoperiod, temperature and precipitation directly control the timing of biological events or they may act instead as cues that set the internal biological clock of the organism (Ausin et al., 2005). In the tropics, variation in precipitation is more likely than temperature to drive phenological patterns (Brearley et al., 2007) and for trees it is a single peak phenomenon in the dry season (Janzen, 1967).

In other studies conducted on the alpine zone, the timing of seasonal flowering is under tight environmental control with temperature and photoperiod playing important roles (Korner, 1999). In the 3000-3900 m altitude zone, the season is longer due to early snow melt and late arrival of snow cover. Consequently, the possible flowering season is longer up to 7 months in this zone. Here species have choice of early flowering, mid -season flowering or late-season flowering, as flowering periods are highly species specific (Korner, 1999) and choices are possible. The trend of flowering phenology shows that flowering starts in April and peaks in July. But even at peak time the number of species involved in peak flowering is comparatively lower than that at higher altitudes because a large number of species occupy this altitude range and different species 
adopt different flowering strategies (early, mid or lateseason flowering). However, with increasing altitude, the duration of flowering season decreases, being 6 months long in the $4200-4500 \mathrm{~m}$ altitude range and 4 months (or less) long above the $4500 \mathrm{~m}$ altitude range. Therefore, choice to flower in a specific period is gradually narrowed with increasing altitude. Above $4500 \mathrm{~m}$ altitude a species has to flower between July and September and this results into gradual increase in flowering peak ( $\%$ species involved in peak flowering) from $65.13 \%$ at $3000-3300 \mathrm{~m}$ range to $100 \%$ above $4500 \mathrm{~m}$ altitude range. Korner (1999) schematically presented the effect of increasing latitude on percentage of species contributing to peak flowering, where he has shown that increasing latitude causes increase in the number of species contributing to peak flowering and maximum $80 \%$ of the species are involved in peak flowering in the alpine zone at $30^{\circ}$ latitude; beyond $30^{\circ}$, it reduces up to $65 \%$ at $70^{\circ}$. In the present study a similar effect has been observed due to increasing altitude. Our results further support Korner's calibration that even at $30^{\circ}$ lat. (most of the sub-alpine -alpine zones in Garhwal Himalaya are between $30^{\circ} \mathrm{N}$ and $31^{\circ} \mathrm{N}$ lat.) variation in altitude affects the number of species contributing to peak flowering. Similar elevation of flowering peak with increasing altitude has been reported from Central Chilean Andes highlands (Arroyo et al., 1981). Thus, increase in altitude or latitude has a similar effect, to great extent, on the number of species contributing to peak flowering in highaltitude areas, though the effect of altitude can elevate peak flowering to $100 \%$ at $30-31^{\circ} \mathrm{N}$ lat. in the Himalaya.

\section{Conclusion}

The results of this study suggest that there is a strong seasonality in phenological pattern of tree species in the temperate forest ecosystems. The spatial and temporal variations in the phenology of the tree species maintain a highly dynamic and productive forest ecosystem. Dharali site showed the initiation of all the phenological characteristics i.e. leaf fall, leaf emergence, appearance of male and female strobili, pollination, cone maturation and seed dispersal in advance as compared to all the other sites. The comparison of the two years phenological data showed that 2013 had the early leaf emergence and prolonged cone maturity and early seed dispersal.

\section{REFERENCES}

Anderson, D.M., Mauk, E.M., Wahl, E.R., Morrill, C., Wagner, A.J., Easterling, D. and Rutishauser, T. (2013). Global warming in an independent record of the past 130 years. Geophysical Research Letters 40: 1-4.

Ausin, I., Alonsco-Blanco, C. and Martinez-Zapater, M. (2005). Int. J. Dev. Biol 49: 689-705.

Arroyo, M.T.K., Armesto, J.J. and Villagran, C. (1981).
Plant phenological patterns in the high Andean Cordillera of Central Chile. J. Ecol 69: 205-223.

Bliss, L.C. (1971). Arctic and alpine plant life cycles. Ann. Rev. Ecol. Syst 2: 405-438.

Both, C., Asch, V. M., Bijlsma, R.G., Van den Burg, A.B. and Visser, M.E. (2009). Climate Change and unequal phenological changes across four trophic levels: constraints or adaptations? Journal of Animal Ecology., 78: 73-83.

Brearley, F.Q., Proctor, J., Suriantata, Nagy, L., Dalrymple, G. and Voysey, B.C. (2007). Reproductive phenology over a 10 -year period in a lowland evergreen rain forest of central Borneo. J. Ecol 95(4): 828-839.

Cannel, M.G.R. and Smith, R.I. (1986). Climatic warming, spring budburst and frost damage on trees. J. Appl. Ecol 23: 177-191.

Chen, X. and $\mathrm{Xu}, \mathrm{L}$. (2012). Temperature controls on the spatial pattern of tree phenology in China's temperate zone. Agr. Forest Meteorol 154-155: 195-202.

Chen, X., Hu, B. and Yu, R. (2005). Spatial and temporal variation of phenological growing season and climate change impacts in temperate eastern China. Glob Change Biol, 11: 1-13.

Chmielewski, F.M. and Rotzer, T. (2001). Response of tree phenology to climate change across Europe. Agricultural and Forest Meteorology 108: 101-112.

Chmielewski, F.M., Müller, A. and Bruns, E. (2004). Climate changes and trends in phenology of fruit trees and field crops in Germany, 1961-2000. Agric. For. Meteorol 121: 69-78.

Chuine, I. (2010). Why does phenology drive species distribution? Philosophical Transactions of the Royal Society B. Biological Sciences 365: 3149-3160.

Cleland, E.E., Chuine, I., Menzel, A., Mooney, A. and Schwartz, M.D. (2007). Shifting plant phenology in response to global change. Trends in Ecology \& Evolution 22(7): 357-365.

Clow, D.W. (2010). Changes in the Timing of Snowmelt and Streamflow in Colorado: A Response to Recent Warming. Journal of Climate 23: 2293-2306.

Crimmins, T.M., Crimmins, M.A. and Bertelsen, C.D. (2009). Flowering range changes across an elevation gradient in response to warming summer temperatures. Global Change Biology 15(5): 1141-1152

Crimmins, T.M., Crimmins, M.A. and Bertelsen, C.D. (2010). Complex responses in onset of spring flowering across a semi-arid elevation gradient. Journal of Ecology 98: 1042-1051.

Davi, H., Gillmann, M. and Ibanez, T. (2011). Diversity of leaf unfolding dynamics among tree species: new insights from a study along an altitudinal gradient. Agr. Forest. Meteorol 151: 1504-1513.

Defila, C. and Clot, B. (2005). Phytophenological trends in the Swiss Alps, 1951-2002. Meteorol. Z 14: 191-196

Diez, J.M., Ibanez, I., Miller-Rushing, A.J., Mazer, S.J., Crimmins, T.M., Crimmins, M. A., Bertelsen, C.D. and Inouye, D.W. (2012). Forecasting phenology: from species variability to community patterns. Ecology Letters 15: 545-553.

Doi, H. and Katano, I. (2008). Phenological timings of leaf budburst with climate change in Japan. Agr. Forest. Meteorol 148: 512-516.

Dunne, J.A., Harte, J. and Taylor, K.J. (2003). Subalpine 
meadow flowering phenology responses to climate change: Integrating experimental and gradient methods. Ecological Monographs 73: 69-86.

Forrest, J., Inouye, D.W. and Thomson, J.D. (2010). Flowering phenology in subalpine meadows: does climate variation influence community co-flowering patterns? Ecology 91: 431-440.

Harte, J., Torn, M.S., Chang, F.R., Felfarek, B., Kinzig, A.P., Shaw, R. and Shen, K. (1995). Global warming and soil microclimate: results from a meadow-warming experiment. Ecological Applications 5: 132-150.

Hulber, K., Winkler, M. and Grabherr, G. (2010). Intraseasonal climate and habitat specific variability controls the flowering phenology of high alpine plant species. Functional Ecology 24: 245-252.

Inouye D.W., and Wielgolaski F.E. (2013) Phenology at High Altitudes. In: Schwartz M. (eds) Phenology: $A n$ Integrative Environmental Science. Springer, 249-272

Inouye, D.W. (2008). Effects of climate change on phenology, frost damage, and floral abundance of montane wildflowers. Ecology 89: 353-362.

Inouye, D.W., Morales, M.A. and Dodge, G.J. (2002). Variation in timing and abundance of flowering by Delphinium barbeyi Huth (Ranunculaceae): the roles of snowpack, frost, and La Niña, in the context of climate change. Oecologia 130: 543-550.

IPCC. (2007). Contribution of working group I to the fourth assessment report of the intergovernmental panel on climate change. In: Solomon, S.D., Qin, M.M., Chen, Z.M., Marquis, K.B., Averyt, M.T. and Miller, H.L. (Eds.), 2007. Climate Change 2007: The Physical Science Basis. Cambridge University Press, Cambridge, UK, 996p.

Janzen, D.H. (1967). Synchronization of sexual reproduction of trees within the dry season in Central America. Evolution 21: 620-637.

Johnson, D.M., Buntgen, U. and Frank, D.C. (2010).Climatic warming disrupts recurrent Alpine insect outbreaks. Proceedings of the National Academy of Sciences, USA 107, 20576-20581 pp.

Jump, A.S., Matyas, C. and Penuelas, J. (2009). The altitudefor-latitude disparity in the range retractions of woody species. Elsevier.

Korner, C. (1999). Alpine Plant Life: Functional Plant Ecology of High Mountain Ecosystem, Springer-Verlag, Berlin, 227p.

Kramer, K. (1995). Phenotypic plasticity of the phenology of seven European tree species in relation to climate warming. Plant Cell Environ 18: 93-104.

Kumar S., Chopra N. and Al-Tawaha A. R. M. S. (2017). Phenological variations in tree and shrub species of a banj oak (Quercus leucotrichophoraA. Camus) dominated forest in Kumaun, Central Himalaya. Advances in Environmental Biology 11(5): 35-43

Menzel, A. (2003). Plant phenological anomalies in Germany and their relation to air temperature and NAO. Clim. Change 57: 243-263.

Menzel, A., Estrella, N. and Schleip, C. (2008). Impacts of climate variability, trends and NAO on 20th century European plant phenology. In: Brönnimann, S., Luterbacher, J.,
Ewen, T., Diaz, H.F., Stolarski, R. and Neu, U. (Eds.) Climate variability and extremes during the past 100 years, vol advances in global change research. Springer 33: 221-233.

Menzel, A., Jakobi, G., Ahas, R., Scheifinger, H. and Estrella, N. (2003). Variations of the climatological growing season (1951-2000) in Germany compared with other countries. Int. J. Climatol 23: 793-812.

Menzel, A., Sparks, T.H. and Estrella, N. (2006). European phenological response to climate change matches the warming pattern. Global Change Biology 12: 1969 1976.

Miller-Rushing, A.J. and Inouye, D.W. (2009). Variation in the impact of climate change on flowering phenology and abundance: An examination of two pairs of closely related wildflower species. American Journal of Botany 96: 1821-1829.

Miller-Rushing, A.J. and Primack, R.B. (2008). Global warming a flowering times in Thoreau's Concord: a community perspective. Ecology 89: 332-341.

Nord, E.A. and Lynch, J.P. (2009). Plant phenology: a critical controller of soil resource acquisition. Journal of Experimental Biology 60: 1927-1937.

Nordli, O., Wielgolaski, F.E. and Bakken, A.K. (2008). Regional trends for bud burst and flowering of woody plants in Norway as related to climate change. Int. J. Biometeorol 52: 625-639.

Parmesan, C. (2006). Ecological and evolutionary responses to recent climate change. Annual Review of Ecology, Evolution, and Systematics 37: 637-669.

Pellerin, M., Delestrade, A., Mathieu, G., Rigault, O. and Yoccoz, N.G. (2012). Spring tree phenology in the Alps: effects of air temperature, altitude and local topography. Eur. J. Forest Res 131(6): 1957-1965.

Rossi, S., Anfodillo, T., Čufar, K., Cuny, H.E., Deslauriers, A., Fonti, P., Frank, D., Gričar, J., Gruber, A., King, G.M., Krausel, C., Morin, H., Oberhuber, W., Prislan, P. and Rathgeber, C.B.K. (2013). A meta-analysis of cambium phenology and growth: linear and non-linear patterns in conifers of the northern hemisphere. Annals of Botany 112: 1911-1920.

Rusch, V.E. (1993). Altitudinal variation in the phenology of Nothophagus pumilio in Argentina. Revista Chilena de Historia Natural 66: 131-141.

Scheifinger, H., Menzel, A., Koch, E., Peter, C. and Ahas, R. (2002). Atmospheric mechanisms governing the spatial and temporal variability of phenological phases in Central Europe. Int. J. Climatol 22: 1739-1755.

Shah S., Verma A. and Tewari A. (2014). Timing of Shifts in Phenological Events in Rhododendron arboreum Smith. Influenced by Climatic Irregularities in Kumaun Regions of Central Himalaya Global Journal of Scientific Researches 2(2):56-59

Wipf, S. (2010). Phenology, growth and fecundity of eight subarctic tundra species in response to snowmelt manipulations. Plant Ecol 207:53-66.

Ziello, C., Estrella, N., Kostova, M., Koch, E. and Menzel, A. (2009). Influence of altitude on phenology of selected plant species in the Alpine region (1971-2000). Climate Research 39: 227-234. 